\title{
Optical coherence tomographic findings at the fixation point in a case of bilateral congenital macular coloboma
}

This article was published in the following Dove Press journal:

Clinical Ophthalmology

2I May 2014

Number of times this article has been viewed

\author{
Kosuke Abe ${ }^{1,2}$ \\ Jumi Shirane ${ }^{2}$ \\ Masuo Sakamoto' \\ Fumi Tanabe' \\ Kazuki Kuniyoshi ${ }^{1}$ \\ Chota Matsumoto' \\ Yoshikazu Shimomura' \\ 'Department of Ophthalmology, Kinki \\ University Faculty of Medicine, Osaka- \\ Sayama, Osaka, Japan; ${ }^{2}$ Nara Hospital, \\ Kinki University Faculty of Medicine, \\ Ikoma, Nara, Japan
}

Background: Congenital macular coloboma is a rare ocular disease that consists of atrophic lesions in the macula with well-circumscribed borders. We report the findings of spectral domain optical coherence tomography (SD-OCT) at the fixation point in a case of bilateral macular coloboma

Case report: The subject is a 4-year-old boy. He visited our hospital at age 1 year and 4 months for the evaluation of strabismus. The fundus examination of both eyes showed round-shaped sharply-demarcated atrophic lesions involving the macula with large choroidal vessels and bared sclera at the base. Immunologic tests including toxoplasmosis, rubella, varicella, herpes virus, and human T-cell leukemia virus were all negative. At age 4 years and 1 month, cycloplegic refraction showed insignificant refractive errors and his best corrected visual acuity was 0.6 bilaterally. The SD-OCT showed a crater-like depression accompanying atrophic neurosensory retina, and the absence of retinal pigment epithelium and choroid. Examination of the fixation behavior by visuscope showed steady fixation with an area $0.5^{\circ}$ nasal to the nasal edge of the atrophic lesion bilaterally. The SD-OCT findings at fixation area showed remaining normal retinal structures involving inner segment-outer segment (IS/OS) junction line.

Conclusion: The findings of SD-OCT have been shown to be useful in the diagnosis of macular coloboma. In the fixation point, the structure of retina and choroid were well preserved.

Keywords: pediatric macular disease, macular structure, strabismus

\section{Introduction}

Congenital macular coloboma appears as atrophic lesions with well-circumscribed borders unilaterally or bilaterally, which result in a nonprogressive decrease in visual acuity. These findings are also seen in patients with intrauterine infection, especially toxoplasmosis. Spectral domain (SD) optical coherence tomography (OCT) is a beneficial tool to make a diagnosis of macular coloboma. We report on the SD-OCT findings in a patient with bilateral macular coloboma. Furthermore, we show the retinal structures at the fixation point.

\section{Case report}

The subject was a 4-year-old boy. He visited our hospital at age 1 year and 4 months for the evaluation of strabismus. He had medical history of ventricular septal defect. The anterior segments were normal. The Hirschberg test revealed an exotropia of $10^{\circ}$. The fundus examination of both eyes showed round-shaped sharply-demarcated atrophic lesions involving the macula with large choroidal vessels and the bared sclera at the base (Figure 1). The atrophic lesion was approximately 1 disc diameter (DD) in height and 1.2 DD in width in the right eye, and 1.2 DD in height and 1.5 DD in width
Correspondence: Kosuke Abe Nara Hospital, Kinki University Faculty of Medicine, I248-I, Otoda, Ikoma, 6300293, Nara, Japan

Tel +81743770880

Fax +8I 743770990

Email abe-k@nara.med.kindai.ac.jp 


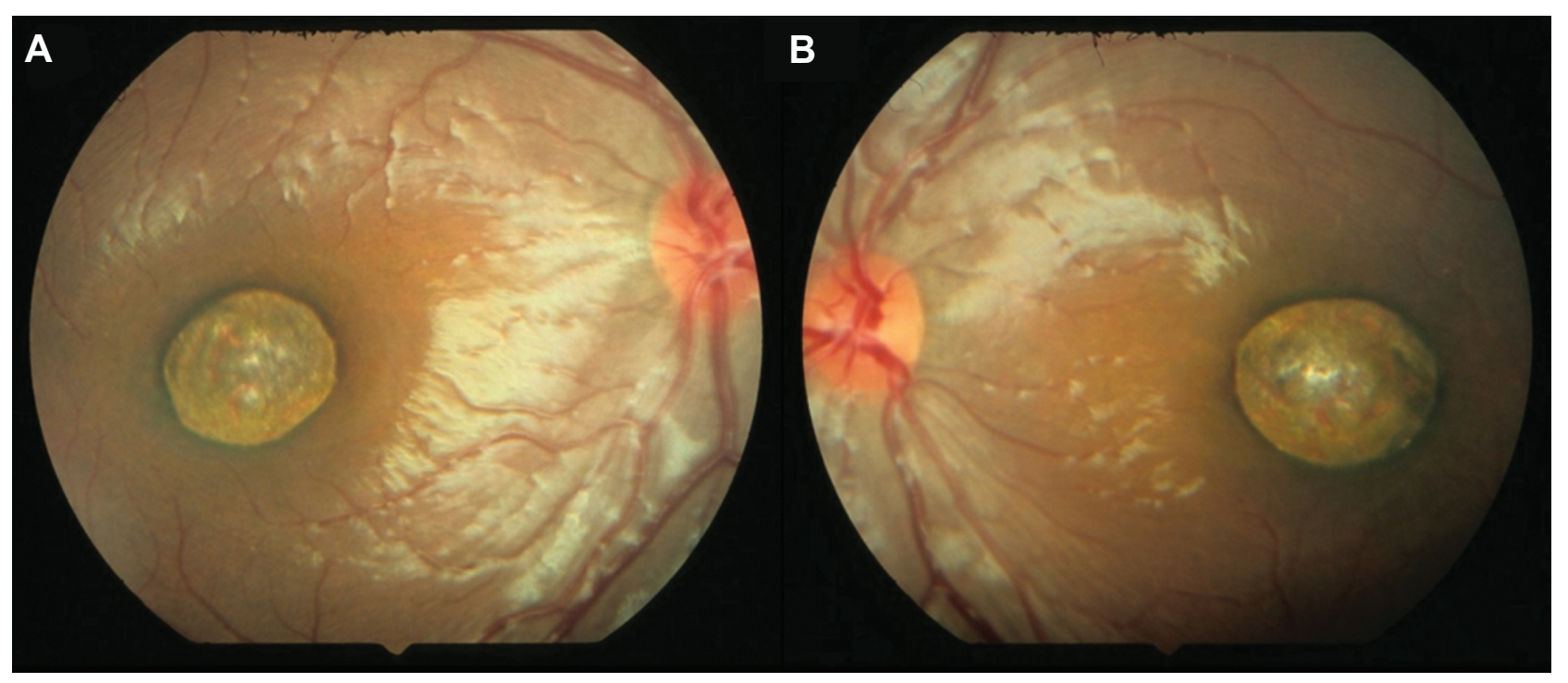

Figure I Fundus photographs taken at age I year and 4 months. Notes: (A) Right eye. (B) Left eye.

in the left eye. Some retinal vessels were disturbed at the margin. Immunologic tests including toxoplasmosis, rubella, varicella, herpes virus, and human T-cell leukemia virus were all negative. Anti-toxoplasma antibody was also negative in his mother. At age 4 year and 1 month, cycloplegic refraction showed insignificant refractive errors and his best corrected visual acuity was 0.6 bilaterally. No stereoacuity was detected with TNO stereo test and Titmus Stereo Test. The fundus examination showed no significant changes except for some pigmentation in the atrophic lesions (Figure 2). Examination of fixation behavior by visuscope showed steady fixation in the normal area close to the nasal edge of the atrophic lesion bilaterally (Figure 2). The SD-OCT (Cirrus HD-OCT; Carl Zeiss Meditec AG, Jena, Germany) showed a crater-like depression accompanying atrophic neurosensory retina, and the absence of the retinal pigment epithelium and choroid (Figure 3). The retinal structures of the fixation area were normal involving IS/OS junction line (Figure 3). In addition, it was not difficult to get the SD-OCT images on him with dilated pupil and without any anesthesia. At age 5 years and 3 months, his best corrected visual acuity was $1.0 \mathrm{OD}$ and $0.8 \mathrm{OS}$.

\section{Discussion}

Congenital macular coloboma is thought to result from incomplete differentiation of the arcuate bundles along the horizontal raphe during development. ${ }^{1}$ However, its morphology of the macular lesion is very similar to that of postinflammatory congenital macular scars resulting from ocular toxoplasmosis. Differentiation between macular coloboma

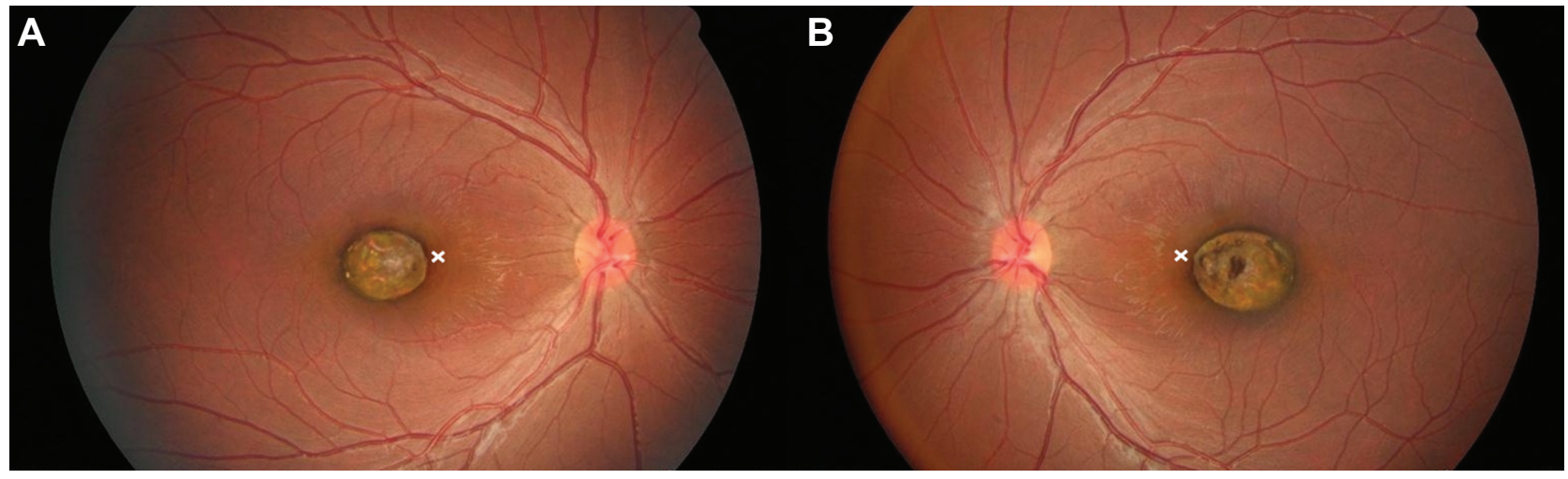

Figure 2 Fundus photographs taken at age 4 years and I month.

Notes: (A) Right eye. (B) Left eye. The white crosses show the fixation points. 


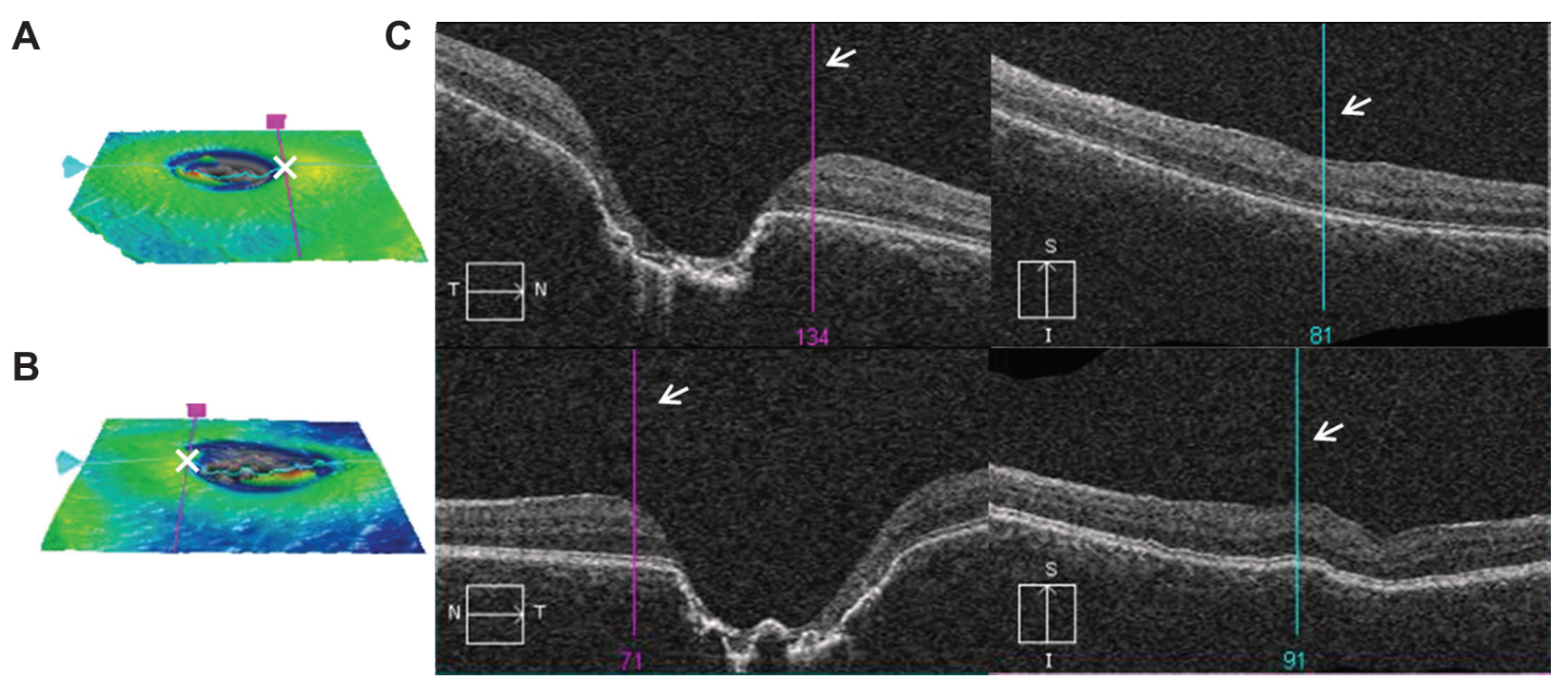

Figure 3 SD-OCT images at age 4 years and I month.

Notes: (A) Right eye. (B) Left eye. (A and B) ILM-RPE map on the macular cube $200 \times 200$. Cross points of vertical and horizontal lines show fixation points (white crosses). (C) B-scans. The bars show the fixation points (white arrows).

Abbreviations: ILM-RPE, internal limiting membrane - retinal pigment epithelium; SD-OCT, spectral domain optical coherence tomography.

and postinflammatory scarring is important to decide the course of treatment. SD-OCT is a beneficial tool in making a differential diagnosis of macular degeneration. ${ }^{2}$

The OCT findings of this case showed absence of the retina and choroid. This structure conformed well to the findings of previous reports..$^{2-5}$ On the other hand, the OCT features of congenital toxoplasmosis macular scars are retinal thinning, retinal pigment epithelium hyper-reflectivity, excavation, intraretinal cysts, and fibrosis. ${ }^{6,7}$ Added to the results of immunologic test, the OCT findings showed that the diagnosis of this patient was congenital macular coloboma.

The fixation points of the patient were located close to the nasal edge of the atrophic lesion. The OCT findings suggested that the retinal structures of the fixation points were well conserved involving IS/OS junction line. It was thought that the patient made adaptation to reflect the image on the comparatively healthy peripheral retina. This phenomenon is known as eccentric viewing. ${ }^{8,9}$ There have been no reports on the structure of the fixation point, although the retinal structure of the fixation point influences the visual acuity and binocularity of patients.

The visual acuity from previous reports ${ }^{1-4,10-12}$ ranged from light perception to 0.8 . However, the atrophic lesions of this case were comparatively smaller than other cases and the conserved normal retinal structures near the fovea resulted in the patient having better visual acuity than those of other cases, although he had exotropia and no stereoacuity. When his dominant eye perceived an image on the fixation point, the fellow eye perceived the image on the atrophic lesion, but the image on the atrophic lesion did not reach the visual cortex. This suggests that his monofixation is not caused by suppression.

\section{Conclusion}

The SD-OCT imaging is helpful in making a diagnosis and determining the course of treatments. Furthermore, the structure of the fixation point has a critical influence on the visual acuity and prognosis of congenital macular coloboma.

\section{Disclosure}

The authors report no conflicts of interest in this work.

\section{References}

1. Sattore J, López JM, Martinez J, Piñera P. Dominant macular colobomata. J Pediatr Ophthalmol Strabismus. 1990;27(3):148-152.

2. Oh JY, Yu YS, Hwang JM, Park KH. Optical coherence tomographic finding in a case of macular coloboma. Korean J Ophthalmol. 2007; 21(3):175-177.

3. Hao S, Liu Z, Xu Y. Optical coherence tomographic features in a case of bilateral macular coloboma with strabismus. Eye Sci. 2011; 26(4):244-246.

4. Hussain N, Mohan Ram LS. Optical coherence tomographic features of unilateral macular coloboma. Indian J Ophthalmol. 2007;55(4): 321-322.

5. Aziz HA, Ruggeri M, Berrocal AM. Intraoperative OCT of bilateral macular coloboma in a child with Down syndrome. J Pediatr Ophthalmol Strabismus. 2011;48 Online:e37-e39.

6. Garg S, Mets MB, Bearelly S, Mets R. Imaging of congenital toxoplasmosis macular scars with optical coherence tomography. Retina. 2009;29(5):631-637.

7. Gallagher MJ, Yilmaz T, Cervantes-Castañeda RA, Foster CS. The characteristic features of optical coherence tomography in posterior uveitis. Br J Ophthalmol. 2007;91(12):1680-1685. 
8. von Noorden GK, Mackensen G. Phenomenology of eccentric fixation. Am J Ophthalmol. 1962;53:642-660.

9. Enoch JN, Johnson CA. The Westheimer function as an indicator of fixation locus. Am J Ophthalmol. 1977;83(4):495-498.

10. Chen MS, Yang CH, Huang JS. Bilateral macular coloboma and pigmented paravenous retinochoroidal atrophy. Br J Ophthalmol. 1992;76(4):250-251.
11. Hayasaka Y, Hayasaka S. Bilatral congenital macular coloboma in a boy with Down syndrome. Eur J Ophthalmol. 2004;14(6):565-567.

12. Yamaguchi K, Tamai M. Congenital macular coloboma in Down syndrome. Ann Ophthalmol. 1990;22(6):222-223.

\section{Publish your work in this journal}

Clinical Ophthalmology is an international, peer-reviewed journal covering all subspecialties within ophthalmology. Key topics include: Optometry; Visual science; Pharmacology and drug therapy in eye diseases; Basic Sciences; Primary and Secondary eye care; Patient Safety and Quality of Care Improvements. This journal is indexed on

\section{Dovepress}

PubMed Central and CAS, and is the official journal of The Society of Clinical Ophthalmology (SCO). The manuscript management system is completely online and includes a very quick and fair peer-review system, which is all easy to use. Visit http://www.dovepress.com/ testimonials.php to read real quotes from published authors. 